\title{
Extreme ultraviolet patterning of tin-oxo cages
}

\author{
Jarich Haitjema ${ }^{\mathrm{a}}$, Yu Zhang ${ }^{\mathrm{a}}$, Michaela Vockenhuber ${ }^{\mathrm{b}}$, Dimitrios Kazazis ${ }^{\mathrm{b}}$, Yasin Ekinci $^{\mathrm{b}}$, \\ Albert M. Brouwer, ${ }^{\mathrm{a}, \mathrm{c}}$ \\ ${ }^{a}$ Advanced Research Center for Nanolithography, P.O. Box 93019, 1090 BA Amsterdam, The \\ Netherlands \\ ${ }^{\mathrm{b}}$ Paul Scherrer Institut, 5232 Villigen, Switzerland \\ ${ }^{c}$ University of Amsterdam, van 't Hoff Institute for Molecular Sciences, P.O. Box 94157, \\ 1090 GD Amsterdam, The Netherlands
}

\begin{abstract}
We report on the extreme ultraviolet (EUV) patterning performance of tin-oxo cages: molecular building blocks that are known to turn insoluble upon EUV exposure, thus having the properties of a negative tone photoresist. In this work, we focus on contrast curves of the materials using open-frame EUV exposures and their patterning capabilities using EUV interference lithography. It is shown that baking steps, such as post-exposure baking (PEB) can significantly affect both the sensitivity and contrast in the open-frame experiments as well as the patterning experiments. In addition, we show that the exchange of the anions of the cage can make a difference in terms of their physical properties. Our results demonstrate the significance of process optimization while evaluating the resist performance of novel molecular materials.
\end{abstract}

Keywords: Tin-oxo cage, EUV lithography, EUV photoresist, interference lithography, organometallic photoresist

\section{Introduction}

Extreme ultraviolet lithography (EUVL) is a promising technique, which can further improve the resolution of patterning in advanced semiconductor manufacturing. Nevertheless, there are still many challenges to be overcome for the introduction of EUVL into high volume manufacturing. One of these challenges is the photoresist performance. The high energy per photon exacerbates stochastic effects when writing small features [1], leading to line edge roughness, and putting limits on the achievable resolution for a given dose. One way to get more chemical conversion per absorbed photon is to use chemical amplification mechanisms such as photoacid generation [2]. However, the photoacids and their quenchers also have an inherent spatial distribution, causing further stochastic effects [3]. Especially quenchers are known to have a large contribution to stochastic noise, as a result of their low concentration in the photosensitive layer [4].

For these reasons, it is interesting to search for alternative materials with improved properties, such as metalcontaining compounds. This material platform has three advantages: it leads to an increase in sensitivity because the higher EUV absorption cross section allows more photons to be absorbed in a thin film. Secondly, it eliminates the need for chemical amplification, removing statistical uncertainties in the position of photoacid generators and quenchers. And thirdly, metal-containing compounds have an improved etch resistance compared to conventional chemically amplified resists [5].

In addition to systems based on nanoparticles, studied by Ober and coworkers [6], organic-inorganic hybrid materials have attracted significant attention [7][8]. Since these materials are molecular, they are well-defined with a single particle size, as opposed to the nanoparticle systems. In the present work, we study tin-oxo cage materials (see Fig. 1) [9]. The compounds consist of a butyl tin oxo cage, with +2 charge, and one or two counterions that neutralize the system.

Extreme Ultraviolet (EUV) Lithography VIII, edited by Eric M. Panning, Kenneth A. Goldberg, Proc. of SPIE Vol. 10143, 1014325 - (c) 2017 SPIE · CCC code: 0277-786X/17/\$18 · doi: 10.1117/12.2257911 


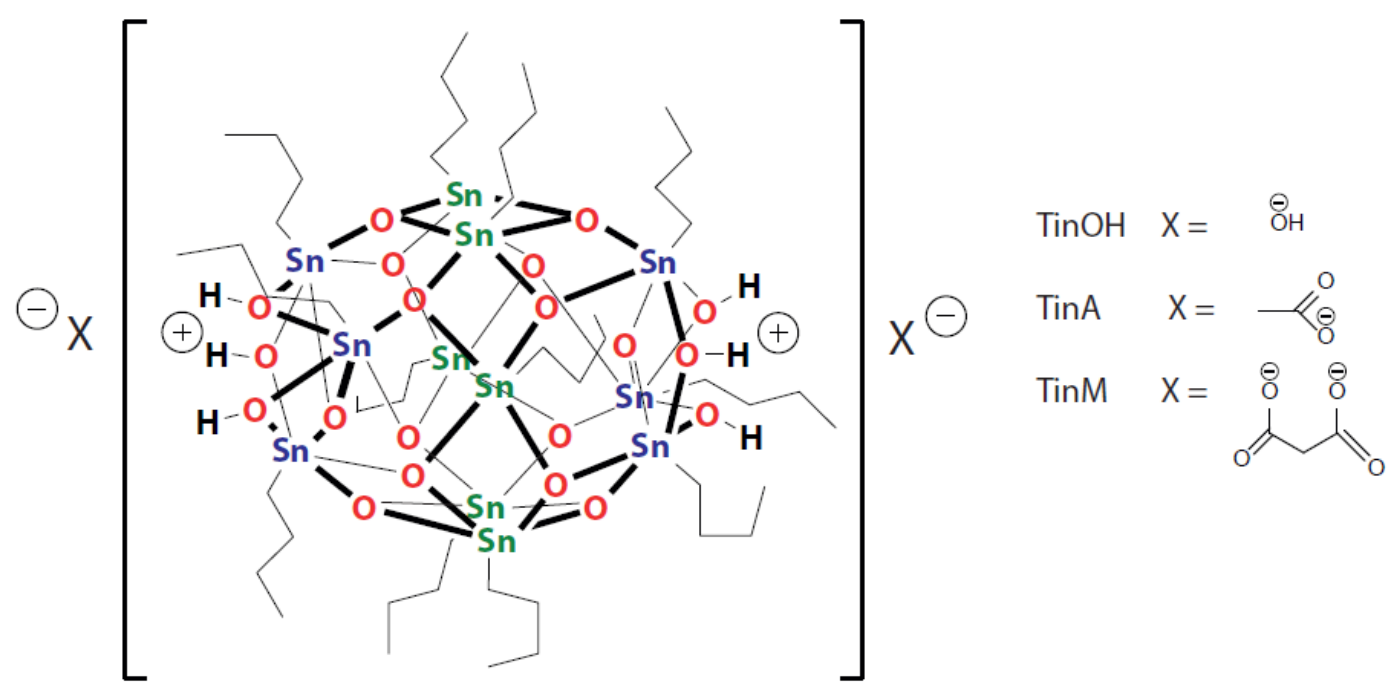

Fig. 1 Tin-oxo cages with three different anions: hydroxide (TinOH), acetate (TinA) and malonate (TinM). Note that for the malonate, the ratio of tin cages to malonate anions is 1:1.

The tin-oxo cage molecules can be regarded as the tin analogue of the silicon-containing silsesquioxane class of compounds. Hydrogen silsesquioxane (HSQ) is the most prominent member of this family, and it has been used to achieve high resolution patterning with both e-beam and EUV lithography [10]. However, the sensitivity of HSQ is very low. We believe that the sensitivity to EUV can be increased significantly by incorporating metal atoms that strongly absorb EUV light. It is not possible to directly replace Si with Sn in HSQ due to the larger size of the Sn atom. However, the tin-oxo cage material is a similar building block with a slightly different shape. The calculated linear absorption coefficient $(\alpha)$ for the tin-oxo cage is $10.8 \mu^{-1}$ (assuming a density of $1.6 \mathrm{~g} / \mathrm{cm}^{3}$ taken from the crystal structure of the cage in tosylate form [11], and using EUV absorption coefficients reported in the literature [12]). The absorption coefficients $\alpha$ of the tin cage materials were also directly measured in a parallel paper [13].

A typical value for the absorption coefficient $\alpha$ of PAG resists is $5 \mu \mathrm{m}^{-1}$, while tin-based materials from Inpria Corp. show an even higher absorption coefficient of around $20 \mu \mathrm{m}^{-1}$ [14]. However, these coefficients cannot be directly related to the sensitivity, because not every absorbed photon induces a change in solubility of the material. Poorly understood loss mechanisms may play a substantial role lowering the sensitivity.

An advantage of the tin-oxo cage system is that two properties can be readily altered: the anions at the side of the cage $\left(\mathrm{X}^{-}\right)$and the organic groups (n-butyl chains in this case). In the present study, we focus on the EUV patterning of some selected materials of this class. In a parallel paper [15], the chemical changes upon exposure to short-wavelength UV light are discussed.

\section{Materials and methods}

\subsection{Materials}

The tin-oxo cage with two tosylates as the anions (TinTs) was synthesized according to a procedure described by Eychenne-Baron et al. [16]. Butylstannoic acid hydrate $\left(\mathrm{BuSnOOH} \cdot \mathrm{xH}_{2} \mathrm{O}\right)$ was mixed with an excess of $p$ toluene sulfonic acid monohydrate $\left(\mathrm{pTsOH} \bullet \mathrm{H}_{2} \mathrm{O}\right)$ in a round bottom ask with toluene as a solvent. The reaction mixture was refluxed overnight under removal of water using a Dean-Stark apparatus. The resulting product was filtered using Celite powder to remove remaining insoluble material. The toluene was then removed under 
reduced pressure to yield a white crude product, which was further purified by recrystallization from 1,4dioxane. Needle-shaped white crystals were isolated.

The dihydroxide form of the tin cage (TinOH) was obtained using a procedure described by Eychenne-Baron et al. [16]. A 20 wt.\% solution of the tosylate form in isopropanol was mixed with a solution of aqueous tetramethylammonium hydroxide (TMAH) in isopropanol. The TMAH was used in excess $(2.3 \times)$. It was observed that the precipitation occurred instantaneously. The resulting suspension was filtered to obtain a white powder.

The diacetate (TinA) and malonate (TinM) forms of the tin cluster were obtained using a procedure described by van Lokeren et al. [17]. The dihydroxide $\mathrm{TinOH}$ was dissolved in tetrahydrofuran (UvaSol, spectroscopic grade) after which two molar equivalents were added of glacial acetic acid (Aldrich), or one molar equivalent of malonic acid (purified by recrystallization), respectively. NMR analysis of these materials was carried out using a Bruker AV-400 NMR spectrometer. The ${ }^{1} \mathrm{H}$ and ${ }^{119} \mathrm{Sn}$ NMR spectra were found to be in agreement with the literature [9][11][16].

\subsection{Preparation of thin films}

For a typical thin film of approximately $40 \mathrm{~nm}$ thickness, a solution is made of $15 \mathrm{mg} / \mathrm{mL}$ of the tin-oxo cage (with any of the counterions) dissolved in toluene using sonication (30 s). In the case of the malonate form, methanol was used as a solvent instead because of solubility issues. Particulates were removed by filtering the solutions using a $0.2 \mu \mathrm{m}$ syringe filter. The solutions were spun on $\mathrm{Si}$ wafers (for interference lithography) and $2 \times 2 \mathrm{~cm} \mathrm{Si} \mathrm{chips} \mathrm{(for} \mathrm{open-frame} \mathrm{experiments)} \mathrm{with} \mathrm{a} \mathrm{spin} \mathrm{speed} \mathrm{of} 2500 \mathrm{rpm}$ for $45 \mathrm{~s}$, with a subsequent soft bake of $30 \mathrm{~s}$ at $90{ }^{\circ} \mathrm{C}$. Both wafers and chips were treated with hexamethyldisilazane (HMDS) prior to spin coating. After exposure, the samples were developed using a 2:1 isopropanol/ $\mathrm{H}_{2} \mathrm{O}$ mixture.

\subsection{EUV exposure}

EUV exposures were carried out at the XIL-II beamline of the Swiss Light Source (SLS) synchrotron at the Paul Scherrer Institut (PSI) with EUV light at $\lambda=13.5 \mathrm{~nm}$ [18]. For the open-frame experiments, $0.5 \times 0.5 \mathrm{~mm}$ areas were exposed to EUV light through a square aperture. For the patterning experiments, a transmission mask was used providing line/space patterns with pitches of 100, 80, 60 and $44 \mathrm{~nm}$.

\subsection{Post-exposure analysis}

AFM analysis was carried out using a Bruker Dimension Icon using the PeakForce tapping (ScanAsysAir) mode. Perpendicular to the resist edge, fields of $40 \times 5 \mu \mathrm{m}$ were scanned with 128 samples/line, using a scan speed of $0.5 \mathrm{~Hz}$. The raw images were corrected for bowing using 1 st and 2 nd order corrections, and film thickness was measured by comparing the height of the film with the height of the substrate. SEM scanning was carried out using a Carl Zeiss SUPRA 55VP SEM with a voltage of $1 \mathrm{kV}$.

\section{Results and discussion}

\subsection{Open-frame experiments: contrast curves}

Contrast curves (also known as H-D curves or characteristic curves) were obtained by measuring the remaining thickness after development as a function of EUV exposure dose using AFM imaging (see experimental section). Firstly, the effect of the anion was investigated. The anion of the tin cage can alter the reaction of the material to EUV excitation [9], but also its physical properties such as solubility. For instance, doubly charged anions such as malonate combined with the cage compound render the material more polymeric in nature because the tin cage can form elongated chains with the doubly charged counterion [17]. The effect of the anion was first investigated by comparing contrast curves of TinOH and the closely related TinA. 
A typical image and a cross-section are shown in Fig. 2. It can be seen that the edge of the resist profile is partly covered by a wave pattern, caused by interference effects. To measure the remaining thickness correctly, the height of the resist was measured as far from the edge as possible.
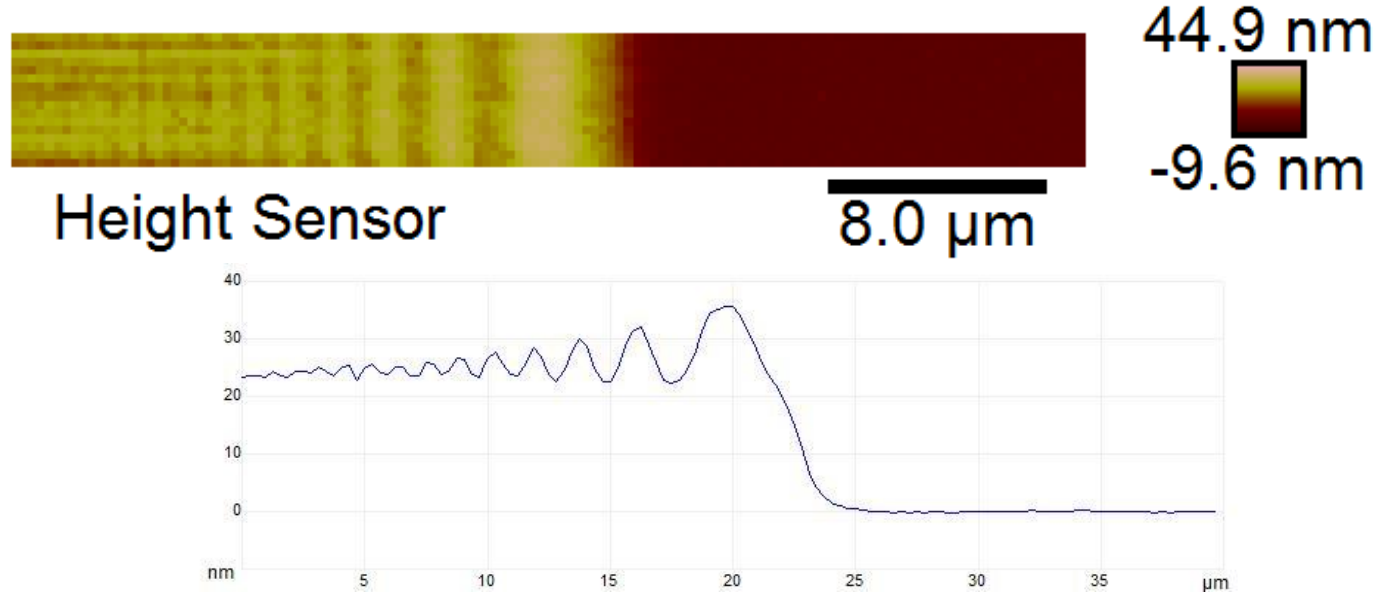

Fig. 2 Typical AFM image of the material ( $\mathrm{TinOH}$ ) edge (top) and averaged edge profile (bottom)

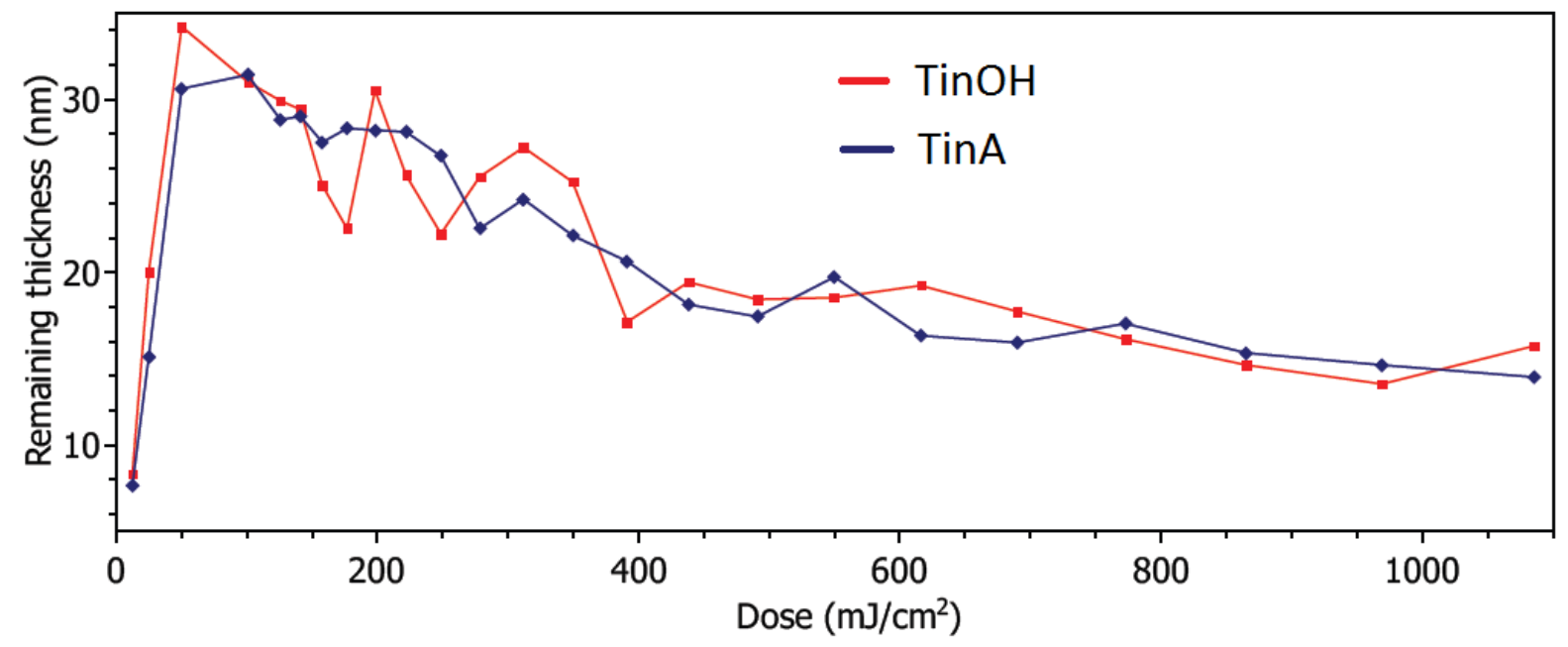

Fig. 3 Fig. 3 Remaining layer thickness as a function of EUV dose for TinOH and TinA. Initial thickness was $\sim 40 \mathrm{~nm}$.

In Fig. 3 the contrast curves are shown for TinOH and TinA, with a $90^{\circ} \mathrm{C}$ post-application bake (PAB) and no post-exposure bake (PEB). The contrast curves of TinOH and TinA exhibit no significant difference. This means that the anions are probably not directly involved in the mechanism that leads to the solubility switch: they could act as non-reactive spacers (as noted by Cardineau et al. [9]). We can observe the onset of gelation at $\sim 10 \mathrm{~mJ} / \mathrm{cm}^{2}$ and a maximum thickness at $\sim 50 \mathrm{~mJ} / \mathrm{cm}^{2}$. At higher doses, the thickness decreases again. This is likely due to loss of organic groups of the resist. For instance, one could think of the loss of some of the butyl chains, in analogy to the results of deep UV exposures [15].

In addition to studying the anion effect, we were interested to see whether improvements to the process alter the contrast curves. In the end, only measurements on an optimized system provide meaningful information about 
photoresist parameters such as sensitivity and contrast. Parameters that were optimized were: developer, development time, PAB and PEB. Firstly, the use of a different developer may improve resist performance. For instance, a higher selectivity for the exposed area with respect to the unexposed may have a larger difference in the solubility rate between the exposed and unexposed area. A few other developers instead of the $2: 1 \mathrm{IPA} / \mathrm{H}_{2} \mathrm{O}$ mixture [9] were tried, such as 2-heptanone mentioned in a patent by Meyers et al. [19]. None of them, however, seemed to significantly improve resist performance or sensitivity. We will therefore only show results obtained with the 2:1 IPA/ $\mathrm{H}_{2} \mathrm{O}$ developer.

Another important processing step is the PEB. This is well-known for chemically amplified resists (CARs): heating the resist after exposure allows diffusion of the photoacids, and induces the removal of the dissolution inhibiting protecting groups [20]. For non-CARs, this connection is less clear. Although photoacid diffusion does not apply here, the heating could still induce additional chemical reactions of species that were formed during the exposure step. This is especially the case since EUV exposures take place in vacuum. Baking is performed under ambient atmosphere, enabling reactions of reactive species with oxygen and moisture.

However, the conditions of the PEB should be carefully tuned, since solubility changes could also occur in material that has not been exposed. This can lead to loss of contrast. In the case of a negative tone resist such as HSQ or the tin-oxo cages, it is essential that the unexposed part can still be fully cleared by the developer.

The baking effect was studied for two different anions: the hydroxide and malonate form of the tin cage. The malonate form is more polymeric in nature and may, therefore, have a different response to heating. The effect of baking at $100^{\circ} \mathrm{C}$ for the hydroxide form can be seen in Fig. 4.

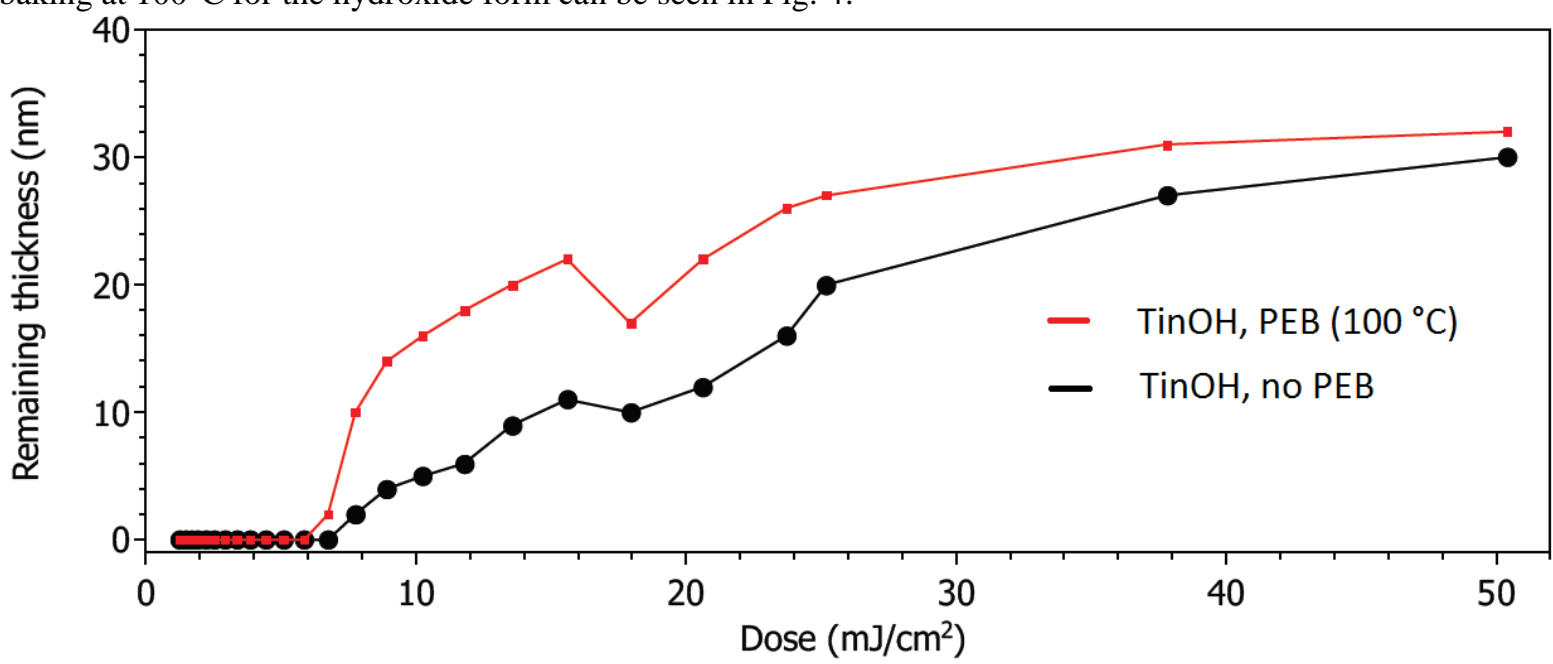

Fig. 4 Contrast curves of TinOH, measured without PEB (black) and with PEB at $100{ }^{\circ} \mathrm{C}$ (red). Initial thickness was $\sim 40 \mathrm{~nm}$.

It can be seen that PEB $\left(100{ }^{\circ} \mathrm{C}, 2 \mathrm{~min}\right.$.) has a significant effect on the sensitivity of the tin-oxo cage material: the onset of gelation shifts to lower dose, and to achieve a remaining thickness of $20 \mathrm{~nm}$, the dose needed is $2 \times$ less. Additionally, the contrast seems to increase, as the initial increase of remaining thickness with dose is $\sim 4 \times$ larger for the baked samples. However, we note that the contrast measured in this way can be different from the theoretical contrast, which is defined as the difference in solubility rate between the exposed and non-exposed parts of the resist [21]. Measuring this more directly, using for instance a quartz crystal microbalance (QCM) would be needed to get a more accurate value.

PEB was also conducted at two higher temperatures: $120^{\circ} \mathrm{C}$ and $150{ }^{\circ} \mathrm{C}$. In this case, however, the unexposed parts of the film became partly insoluble. In the case of $120^{\circ} \mathrm{C}$, the unexposed resist layer was still lower in height than the exposed material, except at very low doses. In the case of $150^{\circ} \mathrm{C} \mathrm{PEB}$, the unexposed layer was 
higher than the exposed parts for all used doses. This confirms that shrinkage of the resist occurs in the exposed parts of the film. PEB at these higher temperatures is probably not suitable for patterning.

PEB was also conducted at $120^{\circ} \mathrm{C}$ for the malonate form (TinM). Surprisingly, the non-exposed resist material was still fully cleared even at this temperature. In addition, the sensitivity of the material was higher than that of all other materials (see Fig. 5). This is possibly related to different solubility properties; the malonate form had to be dissolved in $\mathrm{MeOH}$ instead of toluene. Therefore the exposed resist material may have different (improved) solubility properties as well, being more resistant to baking and showing higher sensitivity. However, the measured contrast of TinM under these conditions appears to be lower than that of TinOH (PEB at $100{ }^{\circ} \mathrm{C}$, Fig. 4), which could explain why the patterning results of TinM were not significantly better.

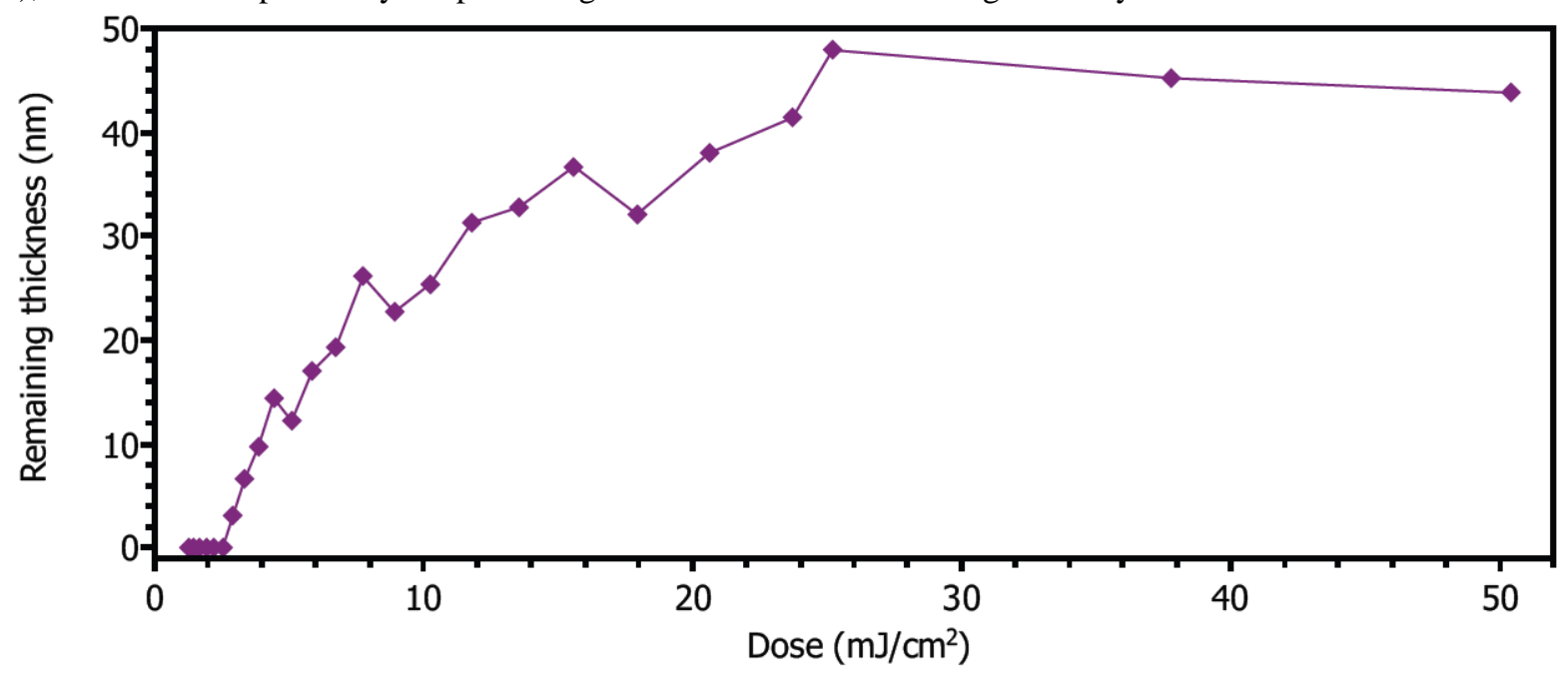

Fig. 5 Contrast curve of TinMal, using a PEB of $120^{\circ} \mathrm{C}$. Initial thickness was $\sim 50 \mathrm{~nm}$.

\subsection{Interference lithography experiments: patterning}

Line patterns were printed in $\sim 30 \mathrm{~nm}$ thick films of the tin cage materials using EUV interference lithography. Transmission diffraction gratings on a $\mathrm{Si}_{3} \mathrm{~N}_{4}$ membrane were used (mask) to create mutually coherent beams which in turn interfere to form the desired interference pattern. In our case, by utilizing two gratings we obtained line/space patterns with half the periodicity of the gratings on the mask [22]. Patterning experiments are important to demonstrate the potential of materials for photoresist applications: a performance is sought with the resolution and sensitivity being as high as possible, and the line edge roughness being minimized. 


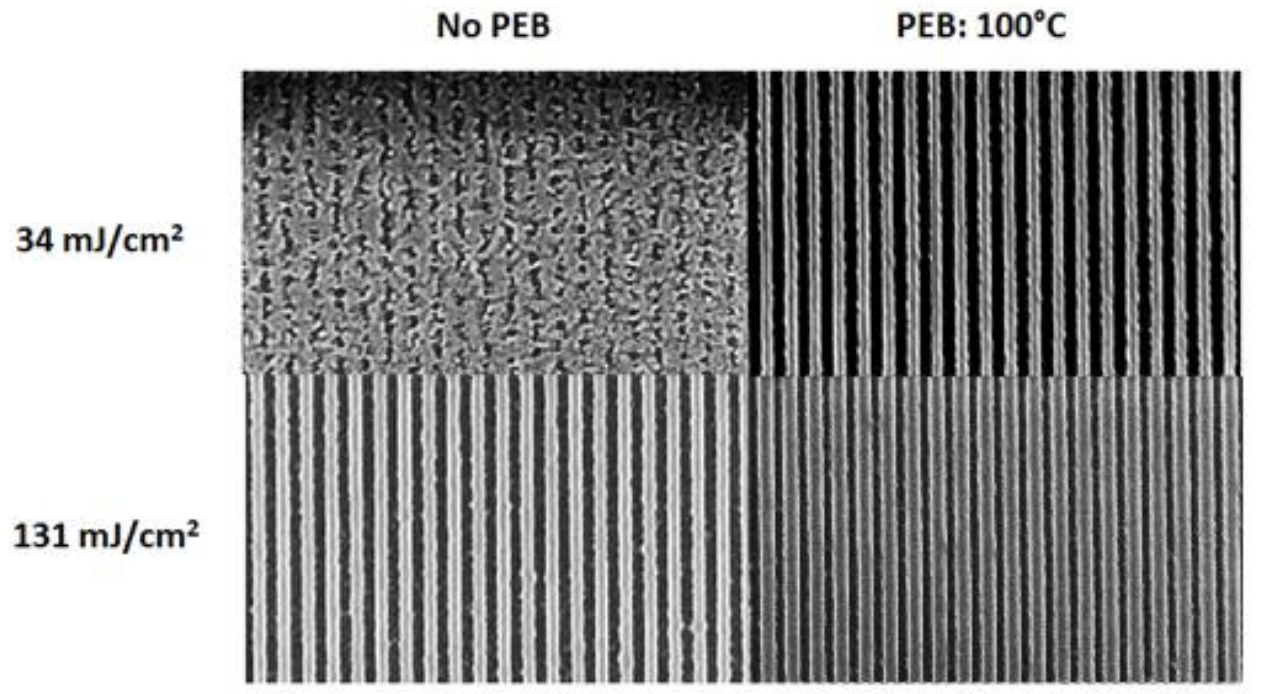

Fig. 6 The effect of PEB on TinOH measured at two different doses $\left(34 \mathrm{~mJ} / \mathrm{cm}^{2}\right.$ and $\left.131 \mathrm{~mJ} / \mathrm{cm}^{2}\right)$ for $50 \mathrm{~nm}$ half-pitch lines.

In Fig. 6 it can be seen that baking has a significant effect on the sensitivity of the TinOH material, similarly to the open frame experiments. Hardly any pattern is visible in the case of $34 \mathrm{~mJ} / \mathrm{cm}^{2}$ without PEB. A reason could be the low contrast (compare Fig. 4). However, the pattern is clearly visible if the sample is baked at $100^{\circ} \mathrm{C}(30$ s) before development, using the same processing conditions. In the case of $131 \mathrm{~mJ} / \mathrm{cm}^{2}$, it can be seen that more material is present in the sample to which PEB was applied: the lines are wider than the spaces in the case of the PEB sample, showing the effects of overexposure. This confirms that a lower dose is required if a PEB is applied. A possible explanation would be that kinetically stable reaction products are formed during the EUV exposure, which react further during the PEB step.

Another issue that was discovered when analyzing the result of the exposures was bridging of the lines. It is an undesirable effect that shows that the optical image is not transferred properly into the resist. It was investigated whether this bridging can be reduced by using different development or rinsing conditions or hard baking. The results are shown in Fig. 7.
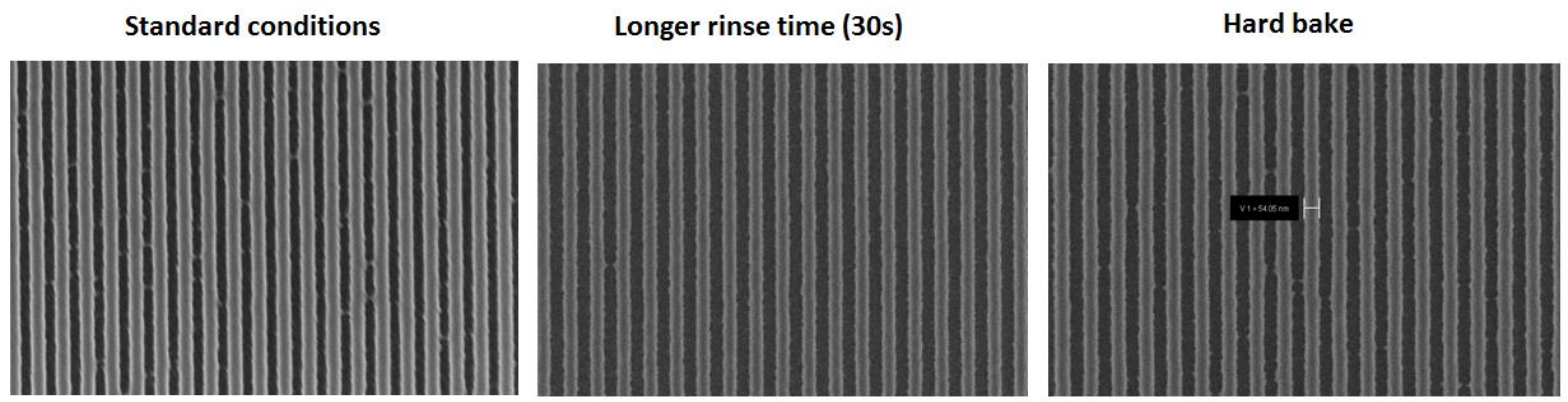

Fig. 7 Minimization of bridging effect, for TinOH using a dose of $110 \mathrm{~mJ} / \mathrm{cm}^{2}$ on $50 \mathrm{~nm}$ HP lines. The regular rinsing time was $10 \mathrm{~s}$. Hardbaking (post-development baking) was performed at $200{ }^{\circ} \mathrm{C}$ for $1 \mathrm{~min}$.

As can be seen, the bridging effect is reduced if a longer rinsing time is used. However, this longer rinsing time also leads to smaller lines relative to the spaces. This implies that the resist is still partly soluble in the rinser $\left(\mathrm{H}_{2} \mathrm{O}\right)$ and that the rinsing should not be performed for a too long time. Hard baking $\left(200{ }^{\circ} \mathrm{C}\right.$ for $\left.1 \mathrm{~min}\right) \mathrm{does}$ not significantly change the pattern. 
Although $80 \mathrm{~nm}$ pitch lines could also be printed, the $60 \mathrm{~nm}$ and $44 \mathrm{~nm}$ pitch lines were significantly more difficult to print: the lines at these pitches seem to be interconnected. Probably this has to do with a problem of the development or rinsing process. The lines seem to detach from the substrate, signaling poor adhesion of the resist film or pattern collapse. Pattern collapse does not seem very likely, however, since the aspect ratio of the pattern is close to $1: 1$. For none of the presently studied materials, patterns at $22 \mathrm{~nm}$ HP could be resolved because of this issue. For $30 \mathrm{~nm}$ HP lines, it was a common phenomenon as well.

The issue could possibly be resolved by two different methods: altering the properties of the rinsing solvent, or changing the aspect ratio by reducing the resist thickness. The first method can reduce the surface tension during the drying stage. For instance, one could think of adding a surfactant to the rinser $\left(\mathrm{H}_{2} \mathrm{O}\right)$, which would drastically reduce surface tension. Additionally, thinner films can easily be made by lowering the concentration in the spin coating solution, although it has to be noted that the aspect ratio is already close to $1: 1$. Therefore, it may be more fruitful to improve the adhesion of the photoresist to the substrate.

The best patterns were created for the tin cage with acetate $\left(\mathrm{CH}_{3} \mathrm{COO}^{-}\right)$anions. This material was significantly less prone than others to pattern collapse or bridging. Two patterns at half pitches of $40 \mathrm{~nm}$ and $30 \mathrm{~nm}$ for this anion can be seen in Fig. 8.

$40 \mathrm{~nm}$ HP lines, $74 \mathrm{~mJ} / \mathrm{cm}^{2}$

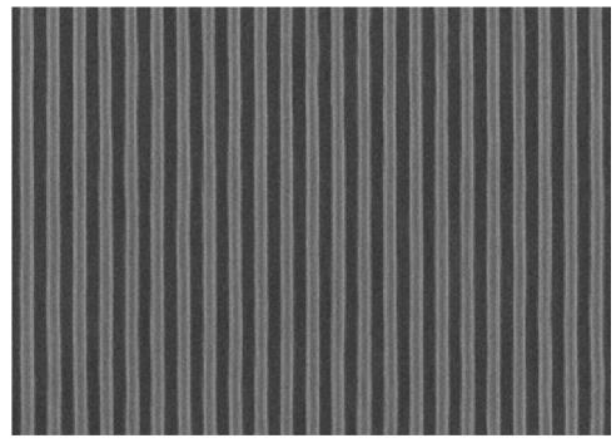

$30 \mathrm{~nm}$ HP lines, $68 \mathrm{~mJ} / \mathrm{cm}^{2}$

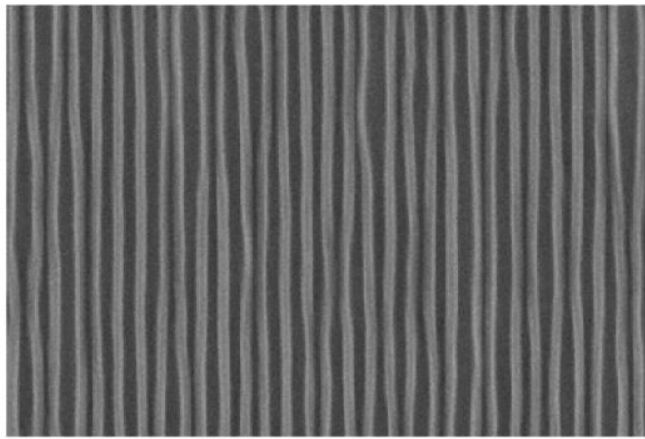

Fig. 8 Interference lithography on TinA. Processing conditions: PAB $90^{\circ} \mathrm{C}(1 \mathrm{~min})$, PEB $100{ }^{\circ} \mathrm{C}(1 \mathrm{~min})$, hard-bake $200{ }^{\circ} \mathrm{C}(1$ $\min )$.

\section{Conclusion}

The EUV patterning of thin films of a small set of tin-oxo cage compounds was investigated. The relatively high packing number of Sn atoms provides a highly absorbing material [13], since $\mathrm{Sn}$ is one of the elements most strongly absorbing at $13.5 \mathrm{~nm}$ [12]. Optimization of the processing conditions provided a better sensitivity than was reported previously [9]. This shows that optimization of the processing is required to evaluate the potential of a particular photoresist material, since parameters such as sensitivity and contrast strongly depend on processing conditions. In particular, post exposure baking was shown to improve the negative tone photoresist performance. This suggests that EUV photoreaction products are formed that can further react during the baking step. While we have achieved progress, it is clear that further improvements are needed to make the materials competitive on an industrial scale. The process of improvement would benefit greatly from a better understanding of the photochemical processes at work. For instance, the relatively low sensitivity suggests that loss mechanisms may be at play in which EUV photons are not converted into the desired solubility change. Reduction of these loss mechanisms could pave the way towards more sensitive resist materials. 


\section{Acknowledgments}

We thank Elizabeth Buitrago and Roberto Fallica (PSI) for help with the experiments, and also thank ASML for providing the initial access to EUVL experiments. Part of this work was performed at Swiss Light Source. This project has received funding from the EU-H2020 research and innovation programme under grant agreement No 654360 having benefitted from the access provided by PSI in Villigen within the framework of the NFFAEurope Transnational Access Activity.

\section{References}

[1] Naulleau, P.; Anderson, C.; Chao, W.; Bhattarai, S.; Neureuther, A.; Cummins, K.; Jen, S.-H.; Neisser, M.; Thomas, B.; EUV Resists: Pushing to the Extreme. J. Photopolym. Sci. Technol. 27, 725-730 (2014)

[2] Shirai, M.; Tsunooka, I.; Photoacid and photobase generators: chemistry and applications to polymeric materials. Prog. Polym. Sc. 21, 1-45 (1996)

[3] Naulleau, P.; Anderson, C.; Chao, W., Bhattarai, S.; Neureuther, A.; Studying Resist Stochastics with the Multivariate Poisson Propagation Model. J. Photopolym. Sci. Technol. 27, blablabla (2014)

[4] Naulleau, P.; Anderson, C.; Chao, W.; Bhattarai, S.; Neureuther, A.; Stochastics and EUV patterning in the 1x-nm Regime. J. Photopolym. Sci. Technol. 6, 747-750 (2016)

[5] Kasahara, K.; Kosma, K; Odent, J.; Xu, H.; Yu, M.; Giannelis, E.P.; Ober, C.K.; Recent progress in nanoparticle photoresist development for EUV lithography. Proc. of SPIE 977604 (2016)

[6] Trikeriotis, M.; Krysak, M.; Chung, Y.S.; Ouyang, C.; Cardineau, B.; Brainard, R.L.; Ober, C.K.; Giannelis, E.P; Cho, K.; A new inorganic EUV resist with high-etch resistance. Proc. of SPIE 83220U (2012)

[7] Amador, J. M.; Decker, S. R.; Lucchini, S. E.; Ruther, R. E.; Keszler, D. A.; Patterning chemistry of HafSOx resist. Proc. of SPIE, 90511A (2014)

[8] Nakagawa, H.; Takehiko N.; Nagai, T.; Recent EUV Resists toward High Volume Manufacturing. J.

Photopolym. Sci. Technol., 6, 739-746 (2014)

[9] Cardineau, B.; Del Re, R.; Marnell, M.; Al-Mashat, H.; Vockenhuber, M.; Ekinci, Y.; Sarma, C.;

Freedman, D.A.; Brainard, R.L.; Photolithographic properties of tin-oxo clusters using

extreme ultraviolet light (13.5 nm). Microelectr. Eng. 147, 44-50 (2014)

[10] Mojarad, N.; Gobrecht, J.; Ekinci, Y.; Beyond EUV lithography: a comparative study of efficient photoresists' performance. Sci. Rep. 5, 9235 (2015)

[11] Eychenne-Baron, C.; Ribot, F.; Steunou, N.; Sanchez, C.; Fayon, F.; Biesemans, M.; Martins, J.C.; Willem, R.; Reaction of Butyltin Hydroxide Oxide with $p$-Toluenesulfonic Acid: Synthesis, X-ray Crystal Analysis, and Multinuclear NMR Characterization of $\left\{(\mathrm{BuSn})_{12} \mathrm{O}_{14}(\mathrm{OH})_{6}\right\}\left(4-\mathrm{CH}_{3} \mathrm{C}_{6} \mathrm{H}_{4} \mathrm{SO}_{3}\right)_{2}$. Organometallics 19, 1940-1949 (2000)

[12] Henke, B.L.; Gullikson, E.M.; Davis, J.C.; X-Ray Interactions: Photoabsorption, Scattering, Transmission, and Reflection at E = 50-30,000 eV, Z = 1-92, At. Data Nucl. Data Tables, 54, 181-342 (1993)

[13] Fallica, R.; Haitjema, J.; Wu, L.; Castellanos, S.; Brouwer, A.M.; Ekinci, Y.; Absorption coefficient and exposure kinetics of photoresists at EUV, Proc. Of SPIE 10143-6 (2017)

[14] Fallica, R.; Stowers, J.K.; Grenville, A.; Frommhold, A.; Robinson, A.P.G.; Ekinci, Y.; Dynamic absorption coefficients of chemically amplified resists and nonchemically amplified resists at extreme ultraviolet

wavelengths. J. Micro/Nanolith. MEMS MOEMS, 15, 033506 (2016)

[15] Zhang, Y.; Haitjema, J.; Liu, X.; Johansson, F.; Lindblad, A.; Castellanos, S.; Ottosson, N.; Brouwer, A.M.; Photochemical conversion of a tin-oxo cage compound studied using hard X-ray photoelectron spectroscopy,

Proc. of SPIE, 10146-5 (2017)

[16] Eychenne-Baron, C.; Ribot, F.; and Sanchez, C.; New synthesis of the nanobuilding block

$\left[(\mathrm{BuSn})_{12} \mathrm{O}_{14}(\mathrm{OH})_{6}\right]^{2+}$ and exchange properties of $\left[(\mathrm{BuSn})_{12} \mathrm{O}_{14}(\mathrm{OH})_{6}\right]\left(\mathrm{O}_{3} \mathrm{SC}_{6} \mathrm{H}_{4} \mathrm{CH}_{3}\right)_{2}$.

J. Organomet. Chem., 567, 137-142 (1998)

[17] van Lokeren, L.; Willem, R.; van der Beek, D.; Davidson, P.; Morris, G.A.; Ribot, F.; Probing 
the anions mediated associative behavior of tin-12 oxo-macrocations by pulsed field gradient

NMR spectroscopy. J. Phys. Chem. C, 114, 16087-16091 (2010)

[18] Mojarad, N.; Hojeij, M.; Wang, L.; Gobrecht, J.; Ekinci, Y.; Single-digit-resolution nanopatterning with extreme ultraviolet light for the $2.5 \mathrm{~nm}$ technology node and beyond. Nanoscale, 7 (2015)

[19] Meyers, S.; Anderson, J.T.; Edson, J.B.; Jiang, K.; Keszler, D.A.; Kocsis, M.K.; Telecky, A. J.; Cardineau, B.J.; Organometallic solution based high resolution patterning compositions and corresponding methods, US patent 2016/0116839 Al

[20] Hinsberg, W.D.; Houle, F.A.; Sanchez, M.I.; Wallraff, G.M.; Chemical and physical aspects of the postexposure baking process used for positive-tone chemically amplified resists. IBM J. Res. \& Dev. 45, 667-682 (2001)

[21] Mack, C.A.; "Lithographic Optimization Using Photoresist Contrast”, Microelectr. Man. Tech.., 14, 36-42 (1991)

[22] N. Mojarad, N.; J. Gobrecht, J.; Ekinci, Y.; Interference lithography at EUV and soft X-ray wavelengths: Principles, methods, and applications, Microelectr. Eng. 143, 55-63 (2015) 